\title{
Role of mental representations in problem solving: Students' approaches to nondirected tasks
}

\author{
Bashirah Ibrahim and N. Sanjay Rebello \\ Department of Physics, Kansas State University, 116 Cardwell Hall, Manhattan, Kansas 66506-2601, USA
}

(Received 17 October 2012; published 10 July 2013)

\begin{abstract}
In this paper, we report on a project concerned with the role of cognition during problem solving. We specifically explore the categories of mental representations that students work with during problem solving of different representational task formats. The sample, consisting of 19 engineering students taking a calculus-based physics course, attempted tasks from the topics of kinematics and work. Profiles were designed to capture the overall actions and reasoning of individual students across the various tasks. Two main profiles emerged from each topic under consideration. They were related to the Johnson-Laird cognitive framework to infer about the kinds of mental constructs. The results indicate that, for both topics, students work primarily at the level of propositional mental representation. When handling the kinematics tasks, a few students construct mental images and none of them can be categorized as using a mental model. In contrast, in the context of work, none of the participants generated a mental image while a minority of the sample was classified as using a mental model. Moreover, a comparison across the two topics indicates the predominance of propositional mental representation.
\end{abstract}

DOI: 10.1103/PhysRevSTPER.9.020106

PACS numbers: 01.40.- $\mathrm{d}$

\section{INTRODUCTION}

In recent years, physics education has placed much emphasis on the application of a model-based approach for teaching and learning. Instructional strategies based on a modeling approach have been used to facilitate conceptual understanding in physics [1-3]. Most of the strategies based on the modeling approach are characterized by two phases. The model development phase focuses on providing experiences that help students construct conceptual and mathematical models that describe a situation. The model deployment phase includes the application of these models to new situations. This phase may lead to changes or refinement in the model previously constructed by the student. According to Gobert and Buckley [4], on the one hand, model-based teaching refers to "any implementation that brings together information resources, learning activities, and instructional strategies intended to facilitate mental model-building both in individuals and among groups of learners." On the other hand, the core of model-based learning lies in "the construction of mental models of phenomena." A mental version of the external representation under consideration is generated, evaluated, improved, or changed and manifested in many ways such as hand movements, verbal, or visual representations such as sketches, diagrams, or material artifacts [2,4]. The hallmark of model-based learning is its central focus on the creation of a mental model of the phenomena which the

Published by the American Physical Society under the terms of the Creative Commons Attribution 3.0 License. Further distribution of this work must maintain attribution to the author(s) and the published article's title, journal citation, and DOI. learner constructs through a set of experiences and then continually applies and refines in different situations.

A key aspect of teaching and learning using a modelbased approach requires that the learner visualize, i.e., form images both internally (mentally) and externally (with paper and pencil or technology) [5]. The importance of external representation lies in the fact that it may provide an associated "mental image" of the physical processes in terms of principles and underlying concepts being considered, hence supporting comprehension [6,7]. However, in many physics textbooks, external representations are often depicted in mathematical forms resulting in difficulty to perceive and grasp the underlying concepts or explanatory principles being highlighted by the theory under consideration [8]. Also, the design of external visual representations is crucial. Faulty depictions or excessive details may lead to failure in capturing the main message being communicated, hence impeding students' construction of mental models and their understanding $[9,10]$. When dealing with external representation, meaningful learning occurs only with the construction of the mental version, i.e., internal representation of the situation or process being considered [11]. It has been further argued that the application of external representations promotes the generation of a mental model which is a key feature in the learning process [12]. However, understanding develops only if there is correspondence between the external representation and its cognitive internal representation. In physics education research, Kohl et al. [13] have explained one of the challenges of using multiple representations with regard to facilitating students to form a coherent internal representation. They argue that, based on the split attention effect or cognitive load theory [14], a learner might find it difficult to coordinate information provided 
through multiple external representations while creating an internal representation of the phenomena. Other studies in science education and cognitive science have identified various factors inhibiting the linking process between mental and external representations $[8,9,12,15,16]$. These include the design (presence of superfluous details and incorrect depictions) and types (predominance of mathematical formulations in textbooks) of representations the students are exposed to. Also noted are the students' level of prior knowledge, surface cognitive engagement where they are poorly motivated to indulge in more profound thought and reasoning processes, and their ways of learning, which are mainly superficial in nature consisting of rote memorization.

Studies concerned with visualization in the field of physics education have, however, focused principally on the role of external representations in the teaching and learning of physics. The efficacy of visual tools such as a microcomputer-based laboratory or computer software for teaching particular topics was explored [17-20]. Students' difficulties in handling particular representations such as diagrammatic and graphical representation in specific topics were investigated [21-25]. Studies were also geared towards exploring problem solving performance and hence differences in strategies with a change in representation [26-28]. The application of multiple representations for conceptual understanding [29,30] and enhancing problem solving performance [31,32] was additionally explored. Moreover, studies have looked into the possible factors leading to the ineffectiveness of teaching and learning based on multiple representations [27,33,34]. Students' inability to relate and translate information within and across representations was found to be the main inhibitor to comprehension, in the learning process and for improved problem solving performance. It was reported that although instructional strategies were designed to teach students to make connections within and across representations, they were not always successful $[35,36]$. Many elements come into play when dealing with an external representation. These include the students' metarepresentational skills, representational competence, and, most importantly, the ability to indulge in cognitive activities such as decoding, interpreting, and deriving information [12].

This study contributes to the area of knowledge concerned with the relationship between external and internal representations. The main aim of the study is to gain insights into students' problem solving strategies which will inform the kinds of cognitive structures constructed by students. The literature does not provide a specific definition for problem solving strategy but highlights different models for problem solving. Polya [37] formulated four steps for handling mathematical problems. These include comprehension of the task, generation and execution of a plan which involves identifying and gathering information as well as patterns, and finally evaluating the effect of the plan. The IDEAL problem solving model was proposed by Bransford and Stein [38]. It stands for identifying and defining the problem, exploring and acting on those procedures, which can be used to solve the problem, and looking back in order to assess the effectiveness of these approaches. However, Jonassen [39] considered problem solving as a cognitive process. The construction, manipulation, and testing of a mental representation play a crucial role in the formulation of a solution. The generation of a mental version of the problem under consideration allows the comprehension of the different aspects which compose the problem and how they are linked as well as the identification of the approaches which can be used to attempt the problem. In our study, we provided students with tasks that were similar to end-of-chapter problems presented in most physics textbooks. Our interest lies principally in how students deal with tasks presented with different kinds of representations requesting a value as the final answer or the generation of a qualitative solution. In physics or science education, it is difficult to have a consistent and definite view of students' mental representations $[8,40]$. However, by referring to their external manifestations within a specific context, we can gain insights into their cognitive constructs [4]. In this case, the students' approaches to solving the problems are a form of external manifestations which are used and related to the Johnson-Laird [41] cognitive framework (shown in Fig. 1) and the theoretical underpinning of the study to infer the kinds of mental representations.

Problem solving is a crucial element and is integral in the physics domain or any scientific discipline. Of main interest in this study is problem solving with respect to different representational formats. This study can provide insights into the use of representations in problem solving in order to facilitate students' construction of mental models. The process of mental model construction can play a crucial role in problem solving. For example, Greca and Moreira [42] found that students who were classified as having a mental model prioritized a qualitative approach,

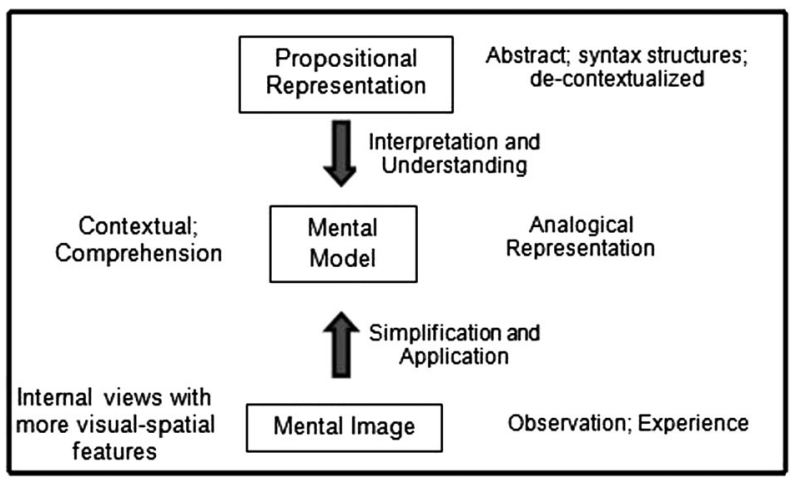

FIG. 1. Types of mental representations according to JohnsonLaird cognitive framework [46]. 
such as including graphs and finding the slope or area of the graph, for problem solving. These students also included visual representations in their problem solution and utilized them to deal with equations. Students who were classified as having a mental model also emphasized the identification and understanding of physics principles or concepts. To encourage the application of these qualitative strategies, thereby promoting the construction of mental models, students should be explicitly taught and provided with opportunities to employ ways in which they can handle problems with different representational formats, rather than focusing principally on the use of equations. The central role of the visual depictions for interpreting physics situations, reasoning purposes, conceptual sense making, and generating quantitative solutions should be highlighted. The findings of this research may also provide grounds for further study. First, the study may inform why students are unable to relate and translate information among different kinds of external representations. The construction of a mental model when dealing with multiple external representations requires making connections between these depictions. However, it was found that students tend to handle multiple representations in isolation and focus on superficial features of the representations $[43,44]$. Second, this study may provide information for exploring how students with different kinds of cognitive constructs handle a particular (single) representation, such as a graphical representation, and investigating the aspects and features of the external representation they focus on and prioritize to generate a solution strategy.

One of the goals of the project is to identify and classify the types of mental representations that students use when they handle problems posed with different external representational formats. We also compare the same students' categories of cognitive constructs across two physics topics. Our research questions are as follows:

(1) What kinds of mental representations do students use when solving nondirected tasks in different external representational formats in the topic of kinematics and work?

(2) How do the types of mental representations that students use compare across the topics of kinematics and work?

As mentioned earlier, we consider a problem solving strategy to include the construction, manipulation, and testing of a mental representation. In the current study, the data analysis consists of two stages. To organize the data, we first identify the problem solving strategies that students employ when handling tasks with a specific format (i.e., a task with a particular representational mode asking for a quantitative or a qualitative solution). Profiles [45] are then generated where we capture key characteristics of problem solving strategies used across the different problem formats. The profiles consequently are composed of various problem solving strategies, all of which can be perceived as emphasizing specific mental representation. This finding allows us to infer that a student having a particular profile can be classified as inclined to some specific mental representation.

Greca and Moreira [42] applied the Johnson-Laird cognitive framework to investigate the kinds of mental representations that engineering students in a calculusbased physics course used to solve problems in electromagnetism. Data were collected from written examinations, quizzes, laboratory activities, and observation of student-student as well as student-instructor discussions. No consideration was made for the formats of the tasks. The present study was also conducted with engineering students, although we have investigated problem solving in different representational formats.

The topics of kinematics and work were chosen because of students' familiarity with these two contexts from the high school level. More importantly, problems in these two topics typically use symbolic or visual representational formats. They also allow for the application of similar procedures such as drawing graphs and/or finding the slope or area under the curve, thus facilitating comparison of a student's similar procedures across different tasks. Finally, Greca and Moreira [42] implemented their study in the context of electromagnetism, principally the concept of field which is abstract in nature, depicted by imaginary lines and taught mainly by focusing on mathematical formulations. In contrast, the topics of kinematics and work are less abstract and can be easily associated with real world events or processes.

\section{THEORETICAL FRAMEWORK}

The Johnson-Laird cognitive framework highlights three main categories of mental representations. (1) Propositional mental representation is made up of a series of symbols, such as equations, formulas, numbers, and definitions which are syntactic abstract structures and meaningless when not integrated within a context. (2) Mental models are constructed by acts of perception or imagination and are analogical representations of real world situations. They are personal, useful only to the person who generates them, and are tentative in nature. They can be discarded or refined with the collection of more knowledge, greater exposure, and familiarity with the situation under consideration. (3) Mental images are based on observations and experiences from the real world. They are "coherent and integrated representations of a scene or object from a particular viewpoint in which each perceptible element occurs only once with all such elements being simultaneously available [41]." They are internal views of mental models with more visual-spatial features allowing perceptible information to be visualized. Greca and Moreira [8] provide a good description using "the cat is on the roof" to differentiate between a mental model and a mental image. According to Greca and Moreira, in order to 
make sense of this sentence, one has to imagine the situation attending principally to the content with details surrounding the visual and spatial aspects of the situation described being implicit. In other words, one may mentally create separate elements for the roof and the cat subordinating the shape, size, and color of these entities. If one takes into account the visual feature of the cat and the roof (for example, a black or gray cat on a red or white roof) and the spatial aspects of these entities (small or big cat on a flat or slanting roof), then an image of the situation is generated since it has a "higher degree of analogical representation to reality." These three kinds of internal representations have different purposes and structures and are personal and abstract in nature with the connection between them being dynamic. The mental model acts as a context for applying propositional representations and mental images hence supporting interpretation and comprehension of the situation or process in question.

According to Greca and Moreira [42], in the context of physics problem solving, students classified with propositional mental representation tend to use definitions and handle mathematical formulations in a rote and mechanical manner. There is no evidence of understanding of the underlying concepts. Students within the category of mental model focus on comprehension of the situation as well as the physics concepts highlighted in the task. Moreover, before dealing with equations they include a diagrammatic representation in their problem solution. Finally, students categorized with mental images refer to the visual depictions they generated to reason about the problem even if they fail to handle the mathematical part of the problem. The outcomes revealed that propositional mental representation predominates.

\section{METHOD}

\section{A. Sample and data collection instruments}

A total of 19 engineering students participated in the study. They were enrolled in Engineering Physics 1, which is a first semester introductory calculus-based physics course. The participants intended to major in engineering (chemical, computer, industrial, or mechanical), biology, or mathematics. However, four of these students had not taken any high school level physics course.

The cohort completed five tasks on the topic of onedimensional kinematics and another set of five tasks on the topic of work. The tasks were nondirected in nature in that they had an open-ended format whereby the students had to design their own procedures for solving the problems. The tasks were presented with three different kinds of representations, namely, linguistic, graphical, and symbolic. The tasks required students to provide either a qualitative or a quantitative answer. These particular representational formats were chosen mainly because they allow for the application of different ways for solving the problem. For the task in a symbolic format, on the one hand, the students may use integration or derivative, or apply other related equations to solve for a quantitative solution. On the other hand, they may draw the graphical version of the given equation and take the slope or area under the graph to solve the problem. When the task is presented in linguistic form, the students may either use equations only or include visual, mainly diagrammatic, representation in their problem solution. Finally, when the tasks are structured in graphical form, the problem may be solved by either taking the slope or area under the given graph or applying mathematical formulations. Additionally, the graphical representation is selected as it is both visual and abstract in nature. It requires interpretation and extraction of physics information embedded by the shapes of the graphs and connection with the various aspects of the graph (for example, quantitative information) in order to make sense of the situation. Similarly, understanding the symbolic format requires interpretation and the ability to link the different syntactic elements which compose the equation. Moreover, students are familiar and at ease with this kind of depiction. Finally, the linguistic format is chosen since it encourages students to mentally or externally form a visual depiction of the situation described and promptly focus on interpretation of sentences embedding the qualitative information. It is also the most commonly used depiction in a problem, as can be seen in many physics textbooks. We did not pose any tasks with a diagrammatic format because our interest lies in exploring whether the students recognize the importance of this particular visual representation and its role in the problem solution when dealing with the mathematical aspect of the task, even when the diagrammatic representation is not explicitly included in the problem.

Across the two topics, we posed four tasks in graphical form which needed to be interpreted to generate either a quantitative answer or a written response (qualitative solution). Only two tasks (one from each topic) were presented as a problem statement (in linguistic form). They required the generation of a value as the final answer. No qualitative solution was requested for the tasks structured in linguistic format. In the study, a qualitative solution is expressed in words. Usually, when students are provided with a task in a linguistic format involving numbers, they are prompted to manipulate equations and quantitative information. It was difficult to structure a task from either topic which will minimize the risk of having students generate an expression or a value as the final answer. The remaining four tasks were presented with a symbolic format requiring interpretation for formulation of a qualitative solution or for determining a value as the final answer. Appendixes A and B provide an overview for the tasks from the topic of kinematics and work, respectively.

\section{B. Administration of instruments}

Solving the problems requires familiarity with the content knowledge, including the interpretation and derivation 
of qualitative information from kinematics equations and motion graphs as well as from functions relating force and position, and graphical depictions relating these two variables. An understanding of the relationship among the motion graphs for position, velocity, and acceleration is also an asset. For the context of work, an awareness of the equations for work done by constant and nonconstant forces is needed. Additionally, the recognition that this particular quantity can also be determined by finding the area under the force-position graph is a benefit. Consequently, the tasks were administered either while the students were covering the relevant topic in class or one week after they had covered the topic. The 10 tasks were completed over four sessions, lasting one hour each, during a period of two months. On a given day, between two and four students were scheduled to individually complete the tasks as well as the interview which immediately followed. In each session, a particular student was presented with a maximum of three tasks to be attempted on an individual basis and in strict sequence. Once a task was completed, the participant was not allowed to view it again, to avoid affecting their performance on subsequent tasks. For each of the 19 students, the four sessions were video recorded and the interviews were additionally audio recorded.

The data collected included students' written solutions which showed their problem solving strategies for the different representational task formats followed by individual interviews with each student. The interviews were used to elicit and provide a clear determination of each student's underlying reasons for adopting these strategies. The justifications were supporting evidence facilitating the categorization of the students' mental representations according to the Johnson-Laird cognitive framework. Overall, during the interview, the students were probed on their use of particular strategies. Questions such as "What prompts you to use this strategy to solve the problem?" and "So you take the area, what leads you to take the area?" were asked. They were also interviewed about alternative approaches to handle the problem as well as justifications for their nonapplication if they were recognized. Illustrations of interview questions for this aspect were, "Are there any other strategies that you can think of to solve this problem?," "Do you have any other ways for solving this problem?," "So, you know you can use the graph to solve the problem but you use this method. What prompts you to use integral here then?," and "So, in here you could have used the method you just described. Did you not think about it?" The students were interviewed regarding the visual representations they used and their role in the problem solution, particularly with respect to the mathematical aspect of the problem. Examples of questions include "Is this how you usually solve problems? I notice that you did not include any sketch. Can you explain why there is no diagram," "What is the role here of the sketch and the force diagram?," "Did you use it with the mathematical part? Did it help you with the mathematical part? If so, how?," and "Did the visual representations help you? If so, how?" Finally, the students were probed for the meaning attributed to physics terms which may be employed ambiguously in the formulation of a qualitative solution as well as the possibility of deriving additional information from the representation presented. For example, "You wrote negative acceleration. Can you elaborate on its meaning?" and "Is there anything else, any more information which you can gather from the graph?" These were the kinds of questions that constituted the semistructured interview protocol.

\section{Analysis}

Research $[8,40]$ has shown that it is difficult to identify and have a consistent view of students' cognitive structures. However, their external manifestations such as reasoning, verbal or visual representations, and hand movements during discussions within a specific context can provide insights about students' mental representation $[2,5]$. In this study we related students' external manifestations such as their written solutions and interview responses to the Johnson-Laird cognitive framework to infer the categories of mental constructs.

The data analysis was mainly qualitative in nature. Of interest are the characteristics of the problem solving strategies employed by individual students across each of the five tasks in a given topic. From the students' written solutions for the problems requesting a qualitative solution, the analysis takes into account whether the student formulated an explanation or a description. An explanation refers to the student's emphasis on the derivation of the physics information presented by the representation. For example, when presented with an acceleration-time graph (question 4, Appendix A), apart from mentioning that the acceleration is in a negative direction or acceleration is zero, the student also mentions something about the object's velocity and direction of motion (Fig. 4). A description is symptomatic of students' focus being mainly on surface displays, such as the syntactic or structural aspect of the representation, and on apparent information. In an illustration interpreting the force-position equation (question 6, Appendix B), the student's written response identifies the variables which form the equation (Fig. 14). Similarly, when interpreting the force-position graph (question 7, Appendix B), the student focuses on reading off the given values for force at the different positions (Fig. 19). For the tasks presented as a problem statement asking for a value as the final answer, our main concern was whether equations were directly manipulated or visual representations were also included in the problem solution. The analysis for the task structured with a graphical format requesting a quantitative solution focuses on whether the problem was solved by using the graph (slope or area) or by 
manipulating mathematical formulations. Finally, for the task posed in a symbolic representation, we consider whether the graphical version of the symbolic representation was drawn and used to attempt the problem or if equations were employed.

Table I summarizes the design, requirements, and analysis of the data collection instruments across the two topics. It particularly focuses on the representational task formats, the strategies (actions) used to solve the problems, and the main themes for the interview questions.

Profiles, defined as a set of descriptors put together to represent the variation in the actions of students across the various tasks [45], from the topic of work and kinematics, respectively, were designed. The analysis method of profiling is basically qualitative in nature and based on the students' problem solving strategies. For a given topic, to construct the profiles, we first identify frequently occurring combinations of problem solving strategies across the five nondirected tasks for each of the 19 students involved in the sample in order to gather key aspects in the characteristics of these strategies. We then generate summaries and structure the descriptions for the strategies in such a way that it captures and represents the main variation in the actions (problem solving strategies) of individual students within the whole sample. During this process, the wordings of the profile descriptors were refined to adequately capture the strategies of the whole cohort leading to the emergence of two main profiles from each topic. The profile allocation was repeated independently by two researchers and an inter-reliability rate of $85 \%$ was obtained. Illustration of profiles (overall description of the sample's problem solving strategies across the five nondirected tasks) in the context of kinematics and work are presented in Figs. 2 and 13, respectively. As stated

TABLE I. Summary of representational task formats and analysis of students' actions and reasoning across the topics of kinematics and work.

\begin{tabular}{|c|c|c|c|}
\hline $\begin{array}{l}\text { Representational } \\
\text { format }\end{array}$ & Task requirement & Problem solving strategies & Themes for interview questions \\
\hline \multirow[b]{2}{*}{$\begin{array}{l}\text { Symbolic } \\
\text { or graphical }\end{array}$} & $\begin{array}{l}\text { Interpret and } \\
\text { formulate } \\
\text { qualitative } \\
\text { answer }\end{array}$ & $\begin{array}{l}\text { Description-focus on superfi- } \\
\text { cial displays or apparent infor- } \\
\text { mation. } \\
\text { Explanation-derive physics } \\
\text { information. }\end{array}$ & $\begin{array}{l}\text { Clarification of ambiguous physics terms. } \\
\text { Possibility of extracting any additional information. }\end{array}$ \\
\hline & Solve for a value & Use of equations-calculus & $\begin{array}{l}\text { Awareness of other ways or qualitative ways to solve } \\
\text { problem. } \\
\text { Reasons for nonapplication of qualitative method if } \\
\text { recognized. } \\
\text { Awareness of concepts: relationship between the three } \\
\text { kinematics graphs; meaning of integral, and its relation } \\
\text { to the notion of area under graph (both kinematics and } \\
\text { topic on work). }\end{array}$ \\
\hline \multirow[t]{2}{*}{ Graphical } & \multirow[t]{2}{*}{ Solve for a value } & $\begin{array}{l}\text { Take slope or area under the } \\
\text { given graph(s). }\end{array}$ & $\begin{array}{l}\text { Reasons for use of strategy. } \\
\text { Awareness of concepts: meaning of integral and its } \\
\text { relation to the notion of area under graph (both kinemat- } \\
\text { ics and topic on work). } \\
\text { Other ways of solving the problem. If use of equations is } \\
\text { mentioned, then reasons for its nonapplication. }\end{array}$ \\
\hline & & $\begin{array}{l}\text { Use of a combination of equa- } \\
\text { tions and slope or area under } \\
\text { graph to solve problems (strat- } \\
\text { egy used only in kinematics). }\end{array}$ & $\begin{array}{l}\text { Reasons for use of strategy. } \\
\text { Awareness of concepts: relationship between the three } \\
\text { motion graphs; mainly, how to obtain displacement from } \\
\text { a given velocity-time graph. If particular concept is } \\
\text { known, probe reasons for its nonapplication. }\end{array}$ \\
\hline \multirow[t]{2}{*}{ Linguistic } & \multirow[t]{2}{*}{ Solve for a value } & $\begin{array}{l}\text { Direct manipulation of equa- } \\
\text { tions. No diagram included. }\end{array}$ & $\begin{array}{l}\text { Reasons for use of strategy. } \\
\text { Views on role of visual or diagrammatic representation } \\
\text { during problem solving. } \\
\text { Reasons for absence of diagram. }\end{array}$ \\
\hline & & $\begin{array}{l}\text { Diagram included. Ignored } \\
\text { or used in relation to the } \\
\text { equations. }\end{array}$ & $\begin{array}{l}\text { Reasons for use of strategy. } \\
\text { Role of diagram in problem solution, in particular, with } \\
\text { respect to the mathematical part of the problem. }\end{array}$ \\
\hline
\end{tabular}




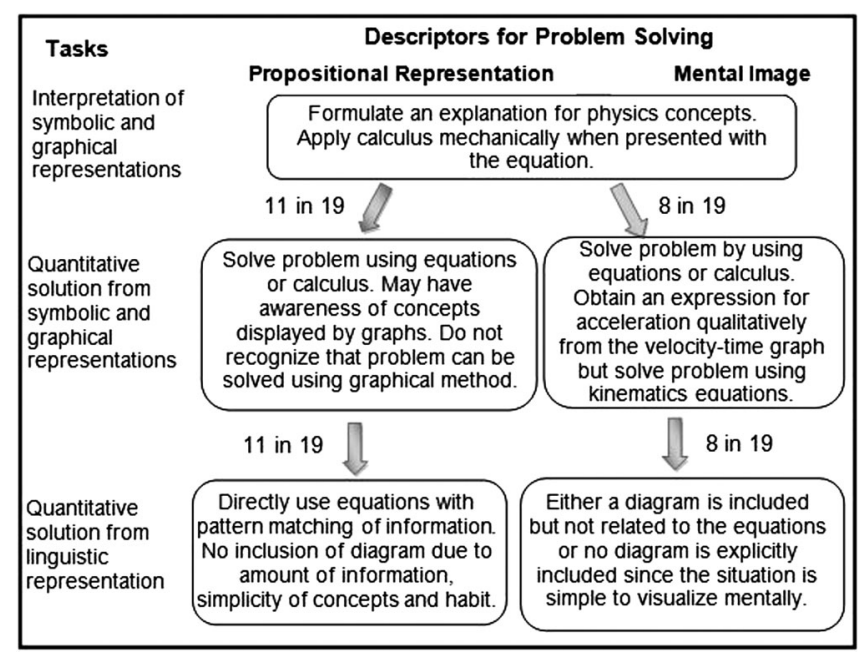

FIG. 2. Descriptors that define students within the profile for the category of propositional representation and mental image in kinematics.

earlier, in order to make inferences about the categories of mental constructs of our participant sample, the profiles are related to the Johnson-Laird cognitive framework. The interview responses were used as additional supporting evidence in the classification of students' categories of cognitive structure. The students' written solutions as well as interview responses are external manifestations which are used to infer the kinds of cognitive structures according to the Johnson-Laird framework. Finally, a comparison was made for the same student's mental representation across the two topics.

Overall, the study consisted of two main stages for analyzing the data. First, the problem solving strategies used by the students when attempting tasks with a specific format were identified. Next, profiles were constructed. These profiles captured and represented the main characteristics of the approaches that students used to handle the different types of problem formats. In this study, a problem solving strategy is regarded as involving the construction, manipulation, and testing of a mental representation. Consequently, the profiling method of analysis allowed for determining if the problem solving strategies comprising a profile indeed emphasized a particular cognitive construct. Thus, it allowed us to infer whether a student could be classified as inclined towards some specific internal representation.

\section{RESULTS}

\section{A. Profiles of students' mental representations in the topic of kinematics}

When handling the nondirected kinematics tasks, we found that about $58 \%$ of the cohort (11 in 19) constructed a propositional mental representation while $42 \%$ (eight in 19) of the cohort generated a mental image. None of the

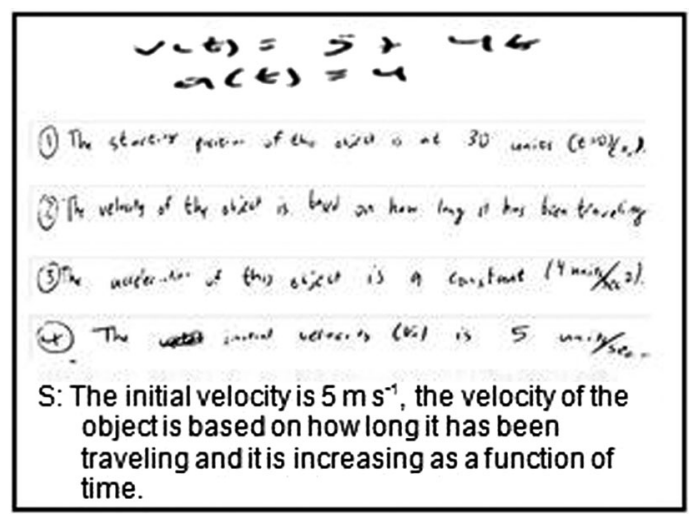

FIG. 3. Interpretation of position equation (question 1).

students were classified within the category of mental model. Figure 2 depicts the characteristics of problem solving strategies for students classified with propositional mental representation and mental image, respectively, when attempting different representational task formats in kinematics. Illustrations of a particular student's actions (depicted by the scans) and interview responses (presented as typed answers) across the five kinematics tasks for the category of propositional representation (Figs. 3-7) and mental image (Figs. 8-12) are also presented. The kinematics tasks are presented in Appendix A.

In the context of kinematics, students categorized with a propositional mental representation are described by their emphasis on pattern matching of information and for manipulating symbolic representation. When the students interpreted the position equation (question 1) as well as the motion graph for acceleration (question 4), they formulated an explanation highlighting the physics concepts. However, when presented with the kinematics equation, they tended to additionally employ calculus in a mechanical manner. Figures 3 and 4 exemplify the description provided.

The same students proceeded to attempt the tasks structured with a symbolic (question 3) and a graphical (question 5) format, respectively, using a quantitative approach for determining a value. Either equations of motion or calculus were applied as the main problem solving

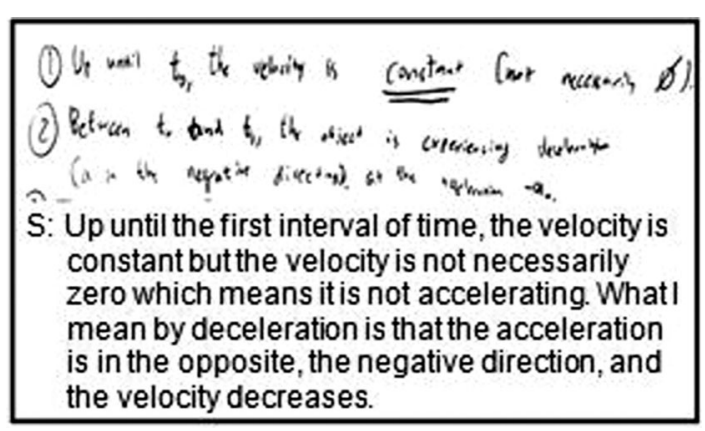

FIG. 4. Interpretation of acceleration-time graph (question 4). 
strategies. During interviews, when probed for alternative approaches, the focus was still on the use of different kinematics equations. None of the students recognized that they could draw the graphical version of the given function or use the provided position-time and velocitytime graphs for handling the tasks. Additionally, when provided with the task posed in graphical form, it was found that nine of the 11 students were able to articulate that the slope and area under the velocity-time graph will yield the acceleration and displacement, respectively. In contrast, a mere four of these 11 students displayed an awareness of this idea when presented with the problem structured in symbolic form. Figures 5 and 6 typify the description provided for the task with a symbolic and a graphical format, respectively.

Finally, when dealing with the problem statement (question 2), equations were directly manipulated to determine a quantitative solution as shown in Fig. 7. The students proceeded by listing the required and given (quantitative) information together with the formulas that fit most of the information. When interviewed for the absence of a visual representation in their solution, the students stated that they did not include a diagram due to their routine pattern for problem solving, which involved manipulating equations only. Other reasons provided are the extent of information and simplicity of the concept presented by the question.

We classified students as having a mental image when they demonstrated a tendency to include a diagrammatic

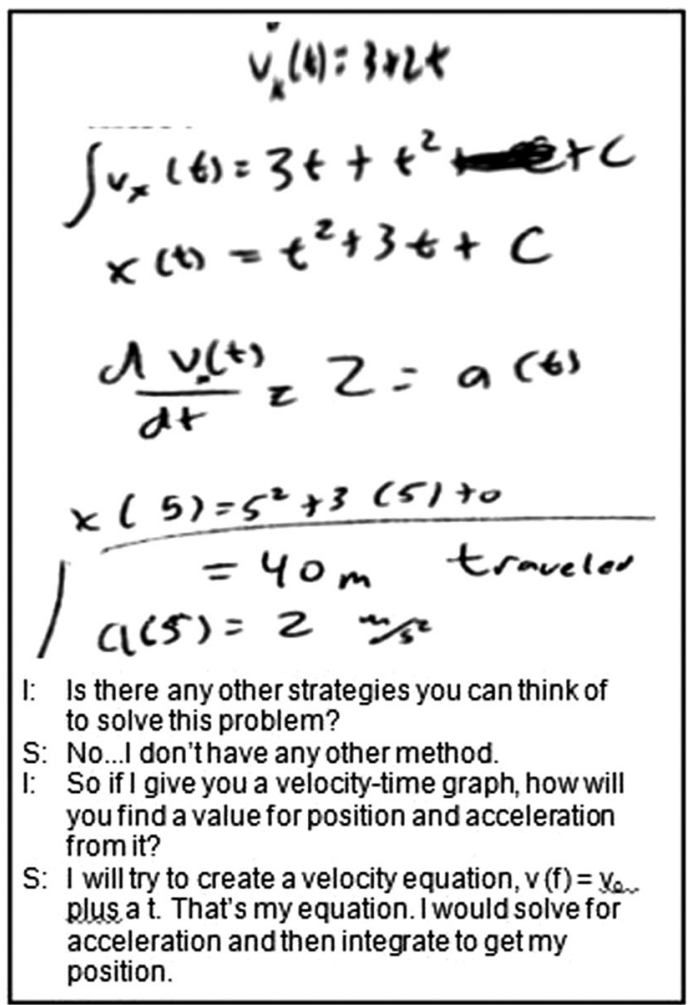

FIG. 5. Solve value from symbolic representation (question 3).

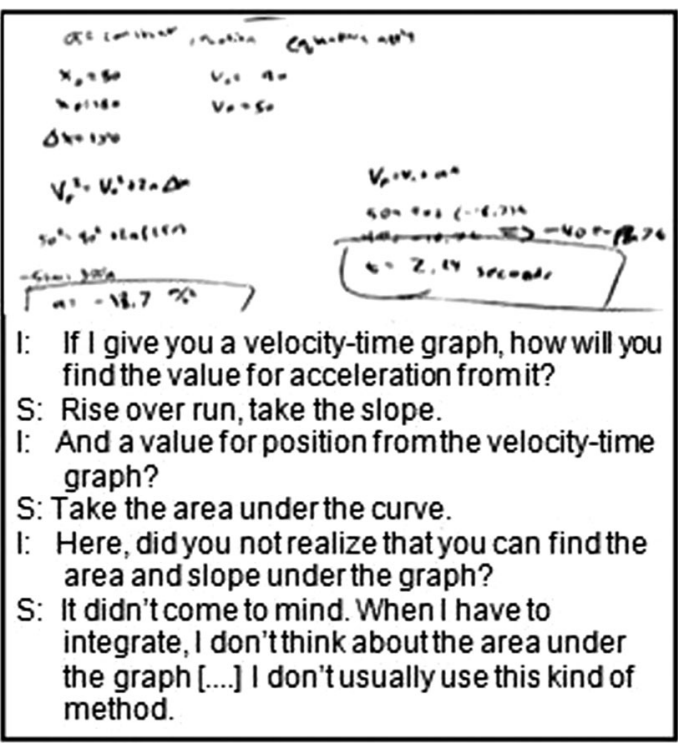

FIG. 6. Solve value from graphical representations (question 5).

representation which may not be linked to the mathematical formulations used. Although they are aware of the relationship among the three motion graphs and may recognize the applicability of the qualitative method (taking the slope or area under the graph) to solve the problem, they prefer manipulating equations. For the tasks posed with symbolic (question 1) and graphical (question 4) representations requiring a qualitative solution, the students formulated a written response in the form of an explanation for the physics information depicted as

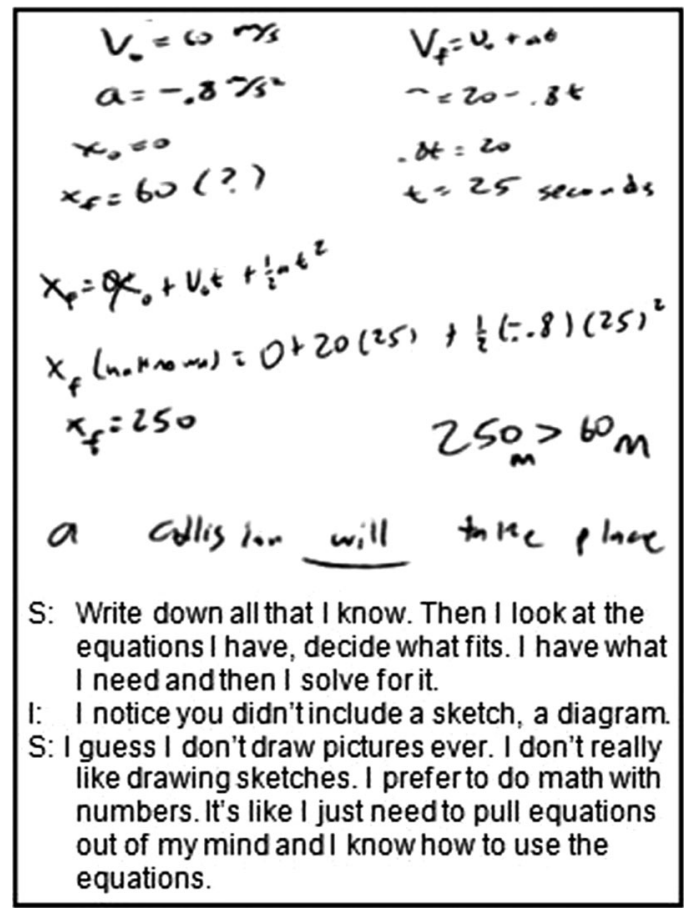

FIG. 7. Solve value from linguistic representation (question 2). 


$$
\begin{aligned}
& r=-5+46 \\
& x=-1
\end{aligned}
$$

The motion as ad dwossional antion. The wation has constont positie acceleration, 4 .

$\mathrm{S}$ : I mean as time goes by the object is continually moving...the velocity is increasing.

FIG. 8. Interpretation of position equation (question 1).

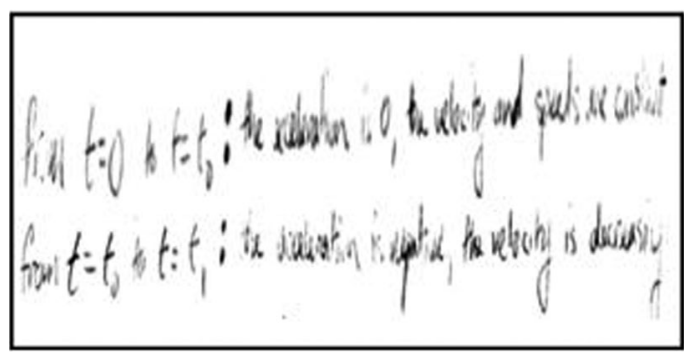

FIG. 9. Interpretation of acceleration-time graph (question 2).

exemplified in Figs. 8 and 9, respectively. Moreover, they applied calculus, in a routine manner, to the position equation to determine an expression for velocity which is further differentiated to obtain a value for acceleration.

For the problem with a symbolic format asking for a quantitative solution (question 3), either calculus (as illustrated in Fig. 10) or other kinematics equations were used. When probed, most (six in eight) of the participants did not recognize that the problem could be solved using the graphical method even if they were aware of the relationship between the motion graphs for position, velocity, and acceleration. Only two students recognized the applicability of the graphical method which they did not employ, as it

$$
\begin{gathered}
\Delta x=3 t+t^{2} \\
3(5)+25=140 \text { units } \\
\operatorname{ax}_{x}(t)=2
\end{gathered}
$$

I: If I give you a velocity-time graph, how will you find a value for the distance and the acceleration?

S: I'll take the area underneath for the distance and for the acceleration, I'll find the slope.

I: So, in here you could have used this method. Did you not think about it?

S: I didn't think of that. It usually doesn't cometo my mind to draw the graph of the equation. It was easier for me to just take the derivative or the integral.

FIG. 10. Solve value from symbolic representation (question 3). was much simpler to use equations with which they were also more familiar.

When solving for a value from the task presented in the form of a position-time graph and velocity-time graph (question 5), the same students proceeded to derive an expression for acceleration by taking the slope under the velocity-time graph. However, this expression was substituted in a kinematics equation for solving the problem. The main reasons provided for this particular action, as illustrated in Fig. 11, include the students' familiarity and ease in manipulating equations, being more acquainted with the notion of slope under the velocity-time graph yielding acceleration which is therefore much more easily identified. Moreover, they were used to translating information mainly into symbolic forms and hence were unsure about how to use graphs to solve the problem.

When solving for a value from the task posed in linguistic form (question 2), a sketch was generated either externally (as depicted in Fig. 12) or mentally. In the latter case, no diagram was explicitly included in the problem solution since it was easy and simple to mentally create a picture of

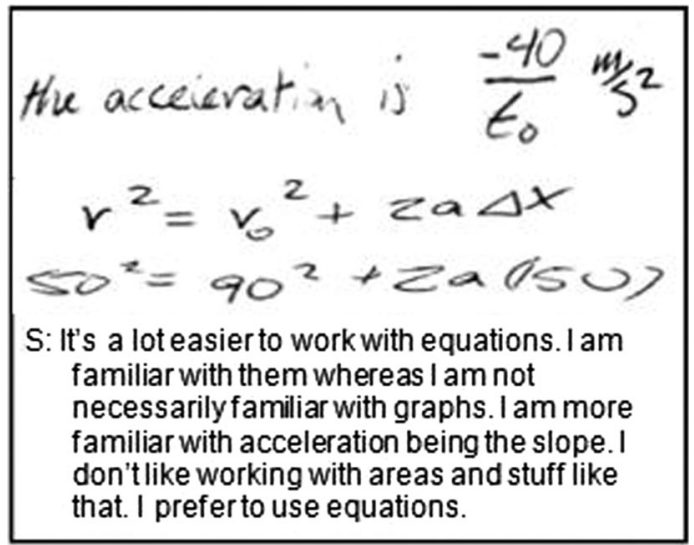

FIG. 11. Solve value from graphical representations (question 5).

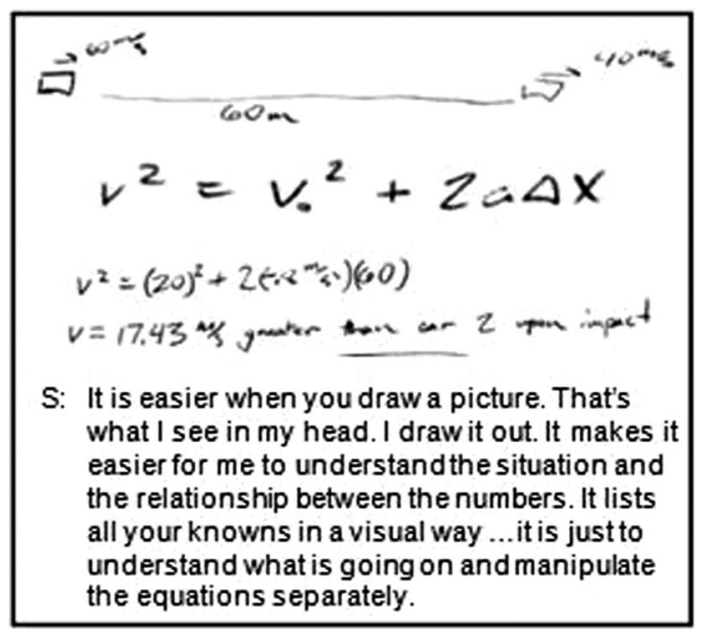

FIG. 12. Solve value from linguistic representation (question 2). 
the situation. In the former case, the visual representation was inclusive but ignored when dealing with the mathematical formulations. The main purpose of the diagram was to have a better comprehension and visualization of the situation described.

\section{B. Profiles of students' mental representations in the topic of work}

For the topic on work, the results indicate that most of the students generated propositional mental representation (79\%, 15 in 19), a minority of the sample constructed a mental model (21\%, four in 19), while none of the students were classified with a mental image. Figure 13 provides an overview of the descriptors which characterize students with propositional representation and mental model when handling representational task formats from the topic on work. Examples of a student's written solutions (portrayed by the scans) and interview responses (represented as typed answers) for the category of propositional representation (Figs. 14-18) and mental model (Figs. 19-22) across the five tasks from the context of work are also presented. The tasks on the topic of work are presented in Appendix B.

In the context of work, for the task with symbolic (question 6) and graphical (question 7) representations requiring a qualitative solution, students with propositional representation tend to mainly formulate a description focusing on superficial displays and apparent information. For the case of the force-position equation, the variables and components of the function were identified as shown in Fig. 14. The students also referred to the corresponding parabolic graphical shape of the symbolic representation.

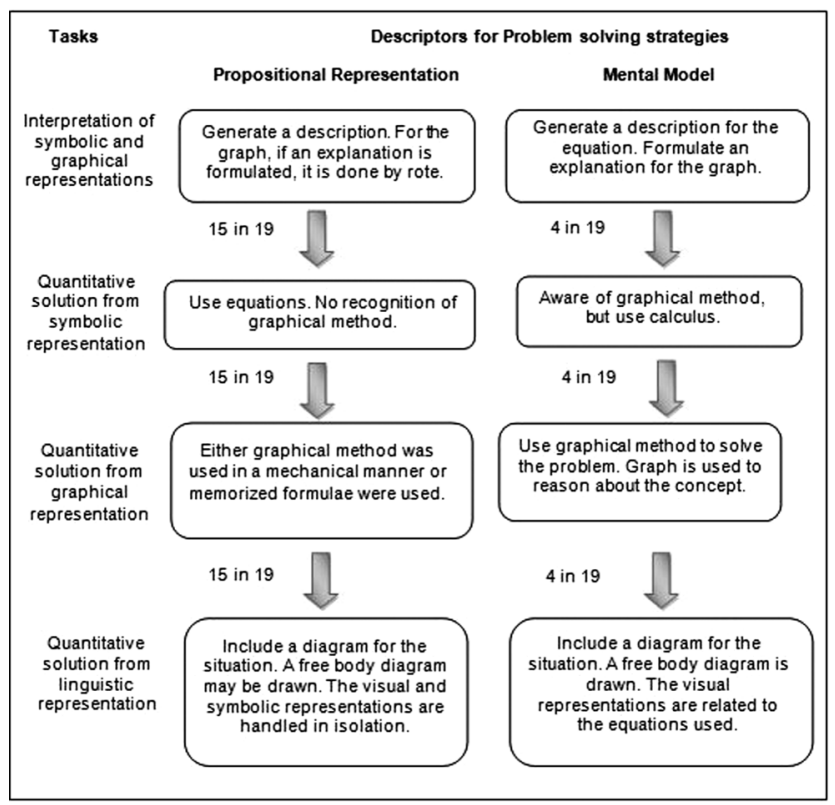

FIG. 13. Descriptors which define students within the profile for the category of propositional representation and mental model in work.

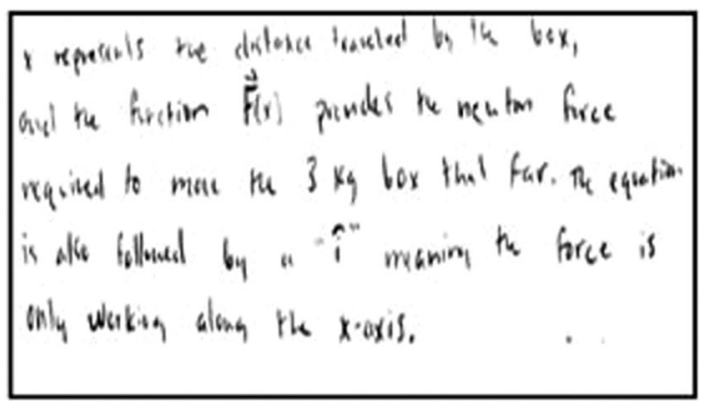

FIG. 14. Interpretation of force-position equation (question 6).

Moreover, the magnitude of the force at different positions was highlighted with the direction of the applied force occasionally mentioned.

For the graphical representation, the description focuses on either reading off values for force at the different positions or highlighting briefly the general trend between the force and position variables from the shape of the graph. The few students (five in 15) who provided an explanation for the given graph stated, in a rote manner (as illustrated in Fig. 15), that the area under the forceposition graph yields work. They also tended to treat the graph as a kinematic one, hence generating irrelevant information.

For the task with a symbolic format asking for a value (question 8), either calculus or the equation for work done by a constant force was employed as the main problem solving strategy. None of these 15 students recognized that the problem could also be attempted by using the graphical method, which is drawing the force-position graph of the given function and taking the area under the graph, as typified by Fig. 16.

To determine a value for work done from the task posed as a pressure-volume graph (question 10), a total of nine in 15 students used a quantitative approach. On one hand, they applied the memorized equation for work done by a constant force to the present situation. On the other hand, they manipulated the units for pressure and volume, thus deriving a formula relating these two variables to obtain the unit for work done in terms of $\mathrm{Nm}$ which is equivalent to Joules. The students then proceeded to solve the problem by taking the difference of the product of these two variables at the specified points. The remaining six participants attempted to solve the problem by taking the area under the

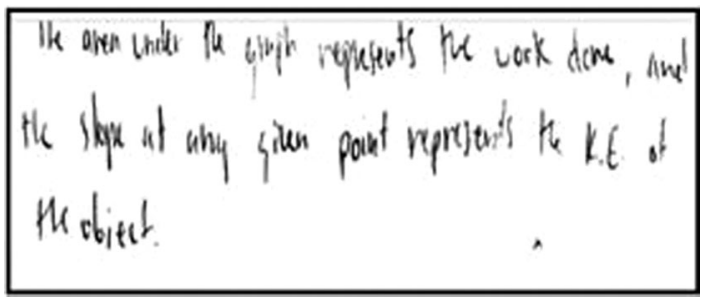

FIG. 15. Interpretation of force-position graph (question 7). 

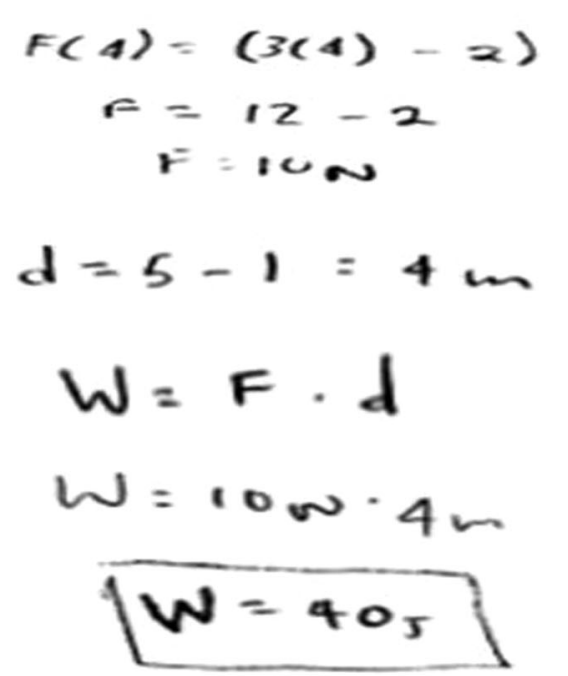

S: The question is asking for work. We are given an equation for force and work is force times distance...I feel it is easiest to solve it in this way.

I: Do you have any other ways for solving the problem?

S: No...I don't know.

I: And did you recognize that you can actually graph it? Draw the graph of the forceversus the distance?

S: I didn't think about that...The only strategy I have in mind is just plug and chug, only force times distance.

FIG. 16. Solve value from symbolic representation (question 8).

graph, by rote, without any evidence of understanding, as depicted in Fig. 17. When interviewed about their actions, they stated that finding the slope or the area under the graphs were the regular procedures which could be used to handle tasks with a graphical format. Additionally, according to the students, since they could not remember the equation to be used, they were provided with a graph and hence the "best guess" was to determine the area.

Lastly, when presented with the problem statement (question 9), the students included visual representations (a sketch for the situation and/or a free body diagram).

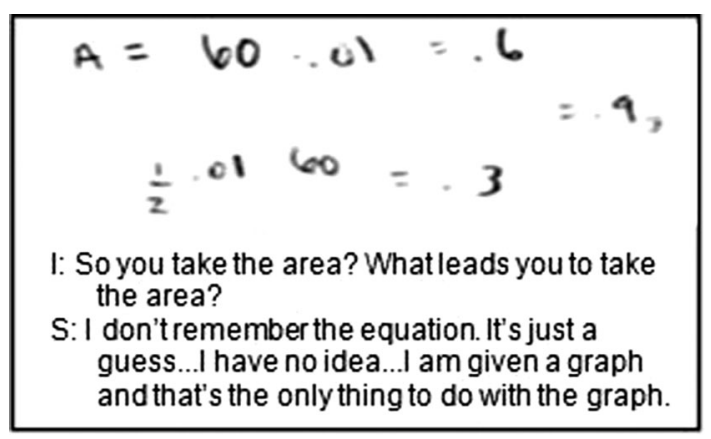

FIG. 17. Solve value from graphical representations (question 10).
However, these visual depictions were ignored when they had to deal with the mathematical part of the problem. The sole purpose of these depictions was to have a better understanding and to better visualize the situation which was described to the students. Figure 18 typifies this observation.

A minority of the students $(21 \%$, four in 19$)$ were classified as working at the level of a mental model. When they had to interpret the symbolic representation (question 6), they formulated a description referring to the parabolic shape of the equation or the magnitude or direction of the applied force at different positions. However, the same students formulated an explanation for the force-position graph (question 7) by referring to the idea that the area under the graph yields the work done. Figures 19 and 20 are representatives.

When they had to solve for a value from the forceposition equation (question 8), they employed calculus, which was suitable to determine work done by nonconstant force although they were aware of the notion of drawing the graphical version of the given equation and determining the area. The students also displayed an understanding that the integral is equivalent to the area under the graph but preferred using equations since it was a much faster and simpler problem solving approach, as illustrated by Fig. 21.

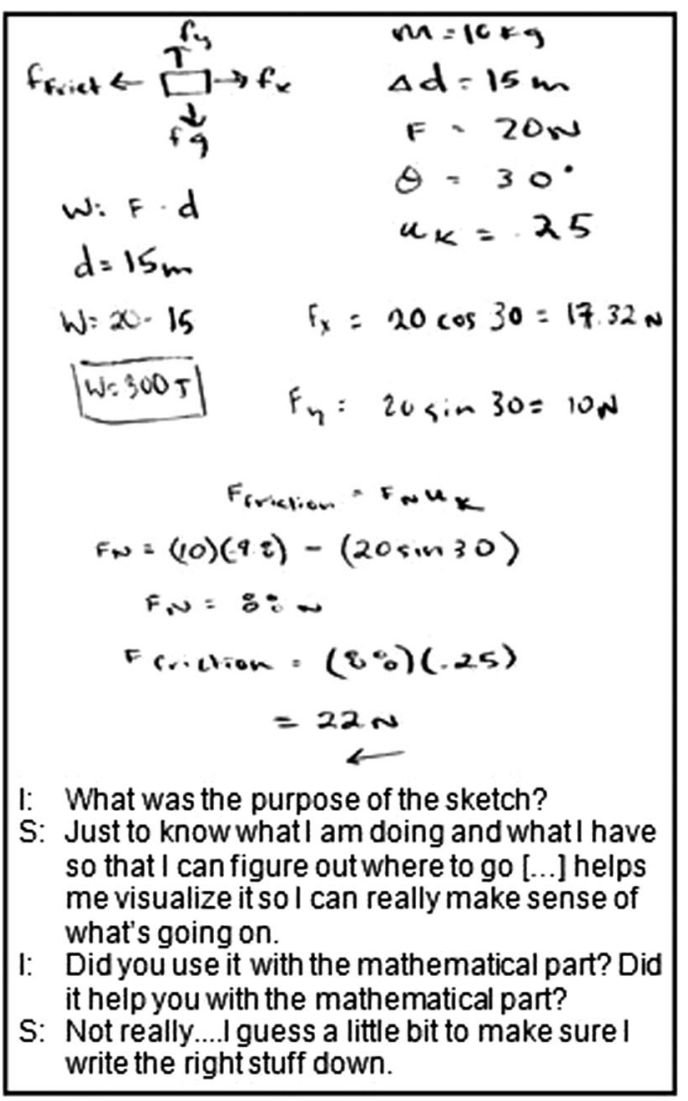

FIG. 18. Solve value from linguistic representation (question 9). 


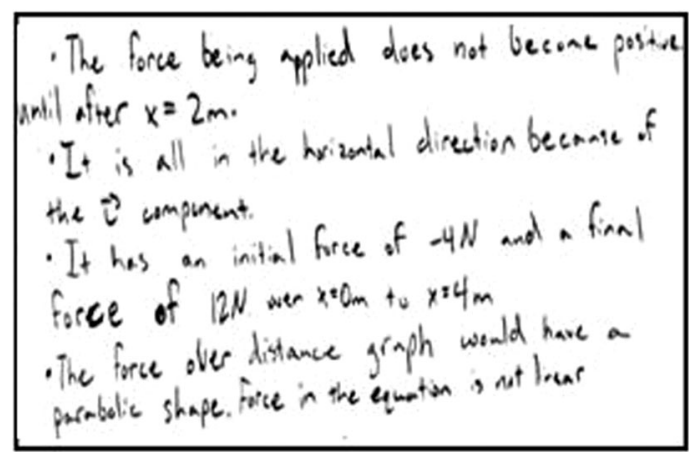

FIG. 19. Interpretation of force-position equation (question 6).

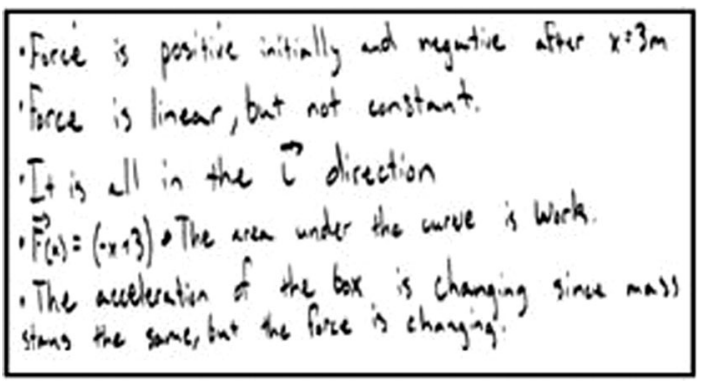

FIG. 20. Interpretation of force-position graph (question 7).

Consequently, when solving for a value from the pressure-volume graph (question 10), all of the students used the graphical method as shown in Fig. 22.

Finally, when working out a quantitative solution from the task with a linguistic format (question 9), all four students included a sketch portraying the situation described as well as a free body diagram. The visual representations were used in conjunction with the mathematical part of the problem. An example is provided in Fig. 23.

$$
\begin{aligned}
& N=F \cdot d=\int F d x=\int_{1}^{s}(3 x-2) d x= \\
& \text { S: Work is force times distance. And so, like, if } \\
& \text { you have a graph or something, if you take the } \\
& \text { area it will give you force times distance as } \\
& \text { well. } \\
& \text { I: Ok, do you have any other ways which you can } \\
& \text { solve the problem? } \\
& \text { S: I could have drawn } 3 x \text { minus 2, a graph, and } \\
& \text { take the area underneath it. } \\
& \text { I: What prompts you to take the integral here? } \\
& \text { S: It is faster and much simpler to use integral } \\
& \text { than drawing the graph and then find the area. } \\
& \text { If you integrate this equation, it's the same } \\
& \text { taking the area under the parabola. }
\end{aligned}
$$

FIG. 21. Solve value from symbolic representation (question 8).

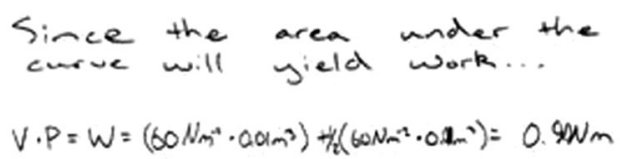

FIG. 22. Solve value from graphical representation (question 10).

S: I started by drawing this diagram [....] I drew a
force diagram, force due to friction which
oppose motion, the normal force, the force of
gravity and I find the components. I said the
total work done would be work done in the y
direction plus work done in the x direction.
I: Ok, did these visual representations help you
with the mathematical part?
S: Yes. They help me to visualize it. I knew what
was going on to put to the components...it's
better drawing the force with the angle. It
gives you a better idea so that way you can't
confuse sine and cosine.

FIG. 23. Solve value from linguistic representation (question 9).

\section{Comparing mental representations across the two topics}

Figure 24 provides an overview of the shift in the types of cognitive structures that the students constructed across the two topics.

The outcome revealed that more than half of the sample (11 in 19, 58\%) consistently work at the level of

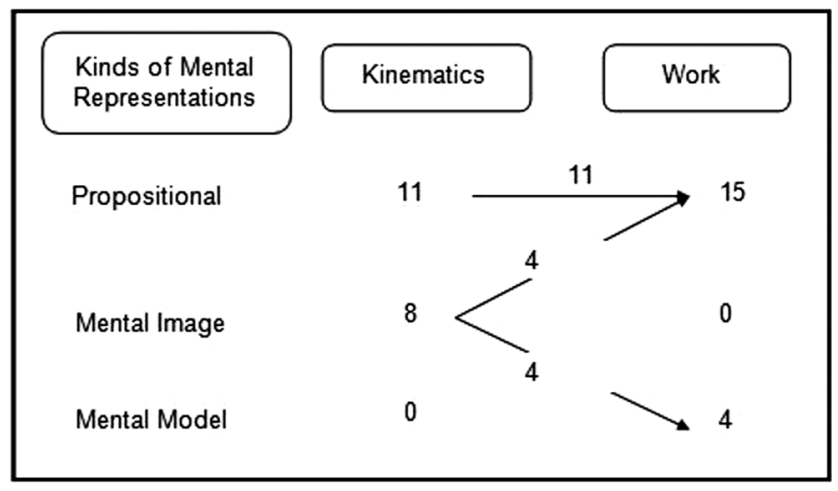

FIG. 24. Categories of mental representations across kinematics and work. 
propositional mental representation across the two topics. The cognitive structure constructed by the remaining students varies according to the topic. Among the eight students who generated a mental image in kinematics, four of them were classified with propositional mental representation when dealing with the tasks on work, and the remaining four students shifted to the category of mental model.

\section{DISCUSSION AND CONCLUSION}

Previous physics education research implemented in the field of visualization has focused mainly on the role of external representation and ways to maximize its effectiveness in the teaching and learning of physics. For the current work, an attempt was made to include the cognitive aspect during physics problem solving via the application of the Johnson-Laird cognitive framework. The framework highlights the kinds of mental representations that students construct by making reference to their external manifestations when handling different representational task formats. We emphasize identifying students' categories of cognitive structures that play a pivotal role in their learning and problem solving. For organizing the data, we first capture the characteristics of the problem solving strategies that students employ to handle each representational task format requesting either a quantitative or a qualitative solution. We then construct profiles across the different types of problem formats, based on the problem solving strategies used. The profiles can be perceived as emphasizing a specific mental representation, hence allowing inferences to be made whereby a student having a specific profile can be categorized as inclined to some specific cognitive construct. The outcomes reveal that, regardless of the topic under consideration, the majority of students (from Figs. 2 and 13) worked at the level of propositional mental representation. In the context of kinematics, less than half of the sample (eight in 19) constructed a mental image with none of them categorized as having a mental model. For the topic on work, very few students (four in 19) were classified with a mental model. None of them generated a mental image. In a study by Greca and Moreira [42] implemented with engineering students handling tasks in the context of electricity and magnetism, the prevalence of propositional mental representation was also observed. This particular outcome is also consistent with the results from the study by Ibrahim [46] involving students with a poor academic and scientific background in solving kinematics tasks. Additionally, the actual study indicates that the majority of the sample (11 in 15) consistently generated propositional representation across the two topics. In a few cases (as depicted in Fig. 24), there was a shift from the category of mental image to either propositional representation or mental model. These findings provide grounds for future research, firstly, to better understand the possible reasons for the predominance of students' use of propositional representations when dealing with different representational task formats and, secondly, to explore the factors leading to students who use propositional representations to maintain their classification as opposed to students who use a mental image. To have better insights into these aspects it may be worthwhile to design future studies to investigate these issues.

The application of the Johnson-Laird cognitive framework in the physics context leads to the emergence of descriptors to define students with propositional representation, mental model, and mental image when handling different representational task formats. Students with propositional representation usually focus on given or apparent information and superficial displays such as the syntactic or structural aspect of the representation. They also prioritize the manipulation of equations with rote memorization and pattern matching of information. Students categorized with a mental model usually display an understanding of concepts (in this case, the meaning attributed to the integral and its relation to the notion of area under a force-position or pressure-volume graph yielding the work done). They appeal principally to the qualitative method (determining the area under the pressure-volume graph) to handle the task posed in a graphical form. They demonstrate recognition regarding the applicability of qualitative strategies, apart from the use of equations or calculus, to handle problems with a symbolic format. Finally, they emphasize the translation of information from linguistic to diagrammatic form which is consequently used in conjunction with the mathematical part of the problem. Students with a mental image do not recognize the use of a qualitative approach to solve for a quantitative solution from a symbolic representational task format although they may display an awareness of the concepts (relationship between the three motion graphs). They tend to use a combination of qualitative (slope or area under graphs) and quantitative (use of equations) approaches to handle the task with a graphical format. They additionally manipulate calculus when interpreting a symbolic representation. They focus on translating information from linguistic to diagrammatic form. The diagram may not be explicitly included in the problem solution, but created mentally. If included, it is ignored, handled independently from the mathematical aspect of the task. Hence, it can be said that students with mental image, although they recognize the importance of visual depictions (such as diagrams which they include mentally or externally and graphs which are partially used) and are aware of concepts (by rote), they still display a preference, and have more confidence in the manipulation of equations. In contrast, students with mental model display an understanding of concepts, employ the visual representations they generated (diagrammatic representation which are related to equations) or they are presented with (graphical format and use of qualitative method), and are aware of a qualitative strategy to handle the task with a symbolic representation even if they prefer 
the use of equations since it is easier and faster. According to the cognitive framework, the construction of the mental model provides a medium for making links between the syntactic (mathematical) and structural (visual) aspects of the task under consideration, thus allowing interpretation and comprehension to take place. Students who construct a mental image handle the (generated) visual representations in isolation. Moreover, the predominance of propositional representation indicates that most of the students in the sample deal with symbolic representations independently of other forms of visual representations. Consequently, students with these two kinds of mental representations can be said to display a poor understanding of the concepts presented by the various tasks. A minority of the sample, from the context of work, can be said to display an understanding of the concepts depicted by the different tasks with the construction of the mental model.

It is argued that the inability to make connections within and across representations is the main factor influencing the effectiveness of using multiple representations for improving conceptual understanding and problem solving performance [12,35]. Previous studies concerned with multiple representations [26,32] have evoked the key importance of students' fluency with different kinds of representations and in translating information among them. In the context of chemistry, Kozma [44] reported that when novice students are presented with multiple depictions, they attended to these representations on an individual basis. They failed to transform information among the various representational modes. They generated descriptions based on superficial displays and direct observations from the representations instead of formulating an explanation for the concepts involved. In our study, students are provided with nondirected tasks. They are not given any prescribed guidance on how to solve the problems. They have to design their own ways and decide on the (visual) representations they want to include in their problem solution. The tasks are posed with a single representational format, for example, a task with a graphical format only or another one presented solely in symbolic form. In contrast, for studies concerned with multiple representations, a given task is often structured with different kinds of representations presented either sequentially $[30,32-34]$ or in parallel $[31,36]$. In our study, the strategies employed across the different tasks posed with a single representational format were considered together and used to infer the kinds of mental representations. Propositional mental representation was found to predominate when handling tasks with single representational format which might explain students' inability to engage in the process of relating and translating information when presented with multiple representations. This study revealed that, when dealing with a single representational format (only linguistic, symbolic or graphical) requiring a quantitative solution, the students think in terms of equations with pattern matching of information rather than the use of a qualitative approach which caters to indepth interpretation and comprehension. Additionally, when interpreting a representation (only graphical or only symbolic), they tend to focus on superficial features rather than extracting maximum physics information. There is a possibility that students' (in)ability to engage in the process of relating and translating information when dealing with multiple representations may be governed by the types of cognitive structures they work with when handling a single representational task format.

The use of external representations promotes the construction of a mental model [12]. The desirable outcome or expectation after instruction or problem solving is that we want our students to construct a mental model which is evidence of understanding according to the cognitive framework. One way in which the construction of a mental model can be promoted is by designing representation-rich teaching and learning materials as well as an environment with particular emphasis placed on the key role of visual representations for reasoning, conceptual sense making, and interpretation. Students should be explicitly taught and provided opportunities to use various ways to handle problems posed with particular representations. It is well known that the application and the manipulating of equations do not guarantee an understanding of the underlying physics concepts. It has also been argued that students' ability and familiarity to handle different kinds of representations and translate information among different representational modes are scientific skills which need to be developed [47].

The inability to make connections within and across representations when dealing with multiple representations may be explained by students' construction of propositional mental representations or mental images when dealing with single representational task formats. In this study, we found that students who use a mental image fail to translate information from the task presented with a symbolic format into a visual format for solving a problem. Additionally, although they do translate information from a linguistic to a visual format, they do not necessarily use the visual representation to generate a numerical solution. Consequently, apart from exposing students to problems that require them to process and translate information between different external representations, students should be facilitated to construct mental models when processing these external representations. Studies which have focused on teaching students to make links between representations $[35,36]$ have found that one of the reasons for the ineffectiveness of these instructional strategies is that students do not willingly relate and translate information. They engage in these processes only when prompted to do so.

One important limitation of this study is its small sample size. It is possible that we were unable to categorize any participants as using a mental model or a mental image in either topic due to the small sample size. A larger sample is 
more likely to include students with all three types of mental representations. From previous studies $[42,46]$ involving cohort sizes of 50 to 179 participants, the number of students identified with a mental model and mental image was still low.

\section{ACKNOWLEDGMENTS}

This work is supported in part by the U.S. National Science Foundation under Grant No. 0816207.

\section{APPENDIX A}

Question 1: Interpretation of symbolic representation

The equation of motion for an object moving along a straight horizontal path is given by

$$
x(t)=30+5 t+2 t^{2}
$$

Write down, in words, everything you can say about the motion of the object.

Question 2: Quantitative solution from linguistic representational format

You are driving at a speed of $60 \mathrm{~m} \mathrm{~s}^{-1}$ when suddenly you see a van $60 \mathrm{~m}$ directly ahead of you also travelling in the same direction at a constant speed of $40 \mathrm{~m} \mathrm{~s}^{-1}$. You immediately apply the brakes and your car starts slowing down at $0.8 \mathrm{~m} \mathrm{~s}^{-2}$. Determine whether a collision will take place.

Question 3: Quantitative solution from symbolic representational format

The equation of motion for an object moving along a straight horizontal path is found to be

$$
\nu_{x}(t)=3+2 t
$$

If the object was in motion for $5 \mathrm{~s}$, what is the distance travelled and acceleration during this time?

Question 4: Interpretation of graphical representation

The acceleration-time graph for an object moving along a straight horizontal path is as shown in Fig. 25.

Write down, in words, everything you can say about the motion of the object.

Question 5: Quantitative solution from graphical representational format

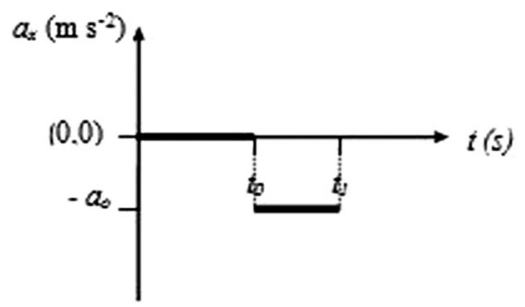

FIG. 25. Kinematics task with graphical format requesting qualitative solution.
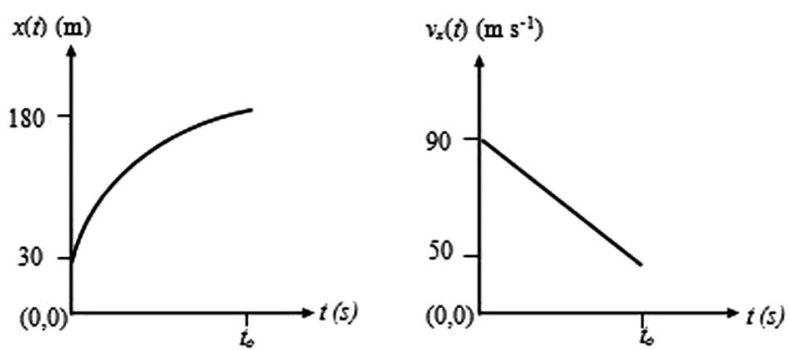

FIG. 26. Kinematics task with graphical format requesting quantitative solutions.

The motion of a truck along a straight horizontal path is shown by the graphs in Fig. 26. Determine the time taken and acceleration of the truck to complete the whole journey.

\section{APPENDIX B}

Question 6: Interpretation of symbolic representation

Write down everything you can say from the force equation $\overrightarrow{\mathbf{F}}(x)=\left(-4+x^{2}\right) \hat{\mathbf{i}} \mathrm{N}$ applied to move the box from an initial position of $0 \mathrm{~m}$ to final position of $4 \mathrm{~m}$.

Question 7: Interpretation of graphical representation

The relationship for the force applied and distance moved by an object from initial position $0 \mathrm{~m}$ to final position $5 \mathrm{~m}$ is shown in Fig. 27.

Write down everything you can say from the graph when the box is moved from an initial position of $0 \mathrm{~m}$ to final position of $5 \mathrm{~m}$.

Question 8: Quantitative solution from symbolic representation

The force applied in moving a $5 \mathrm{~kg}$ box on a frictionless horizontal surface is given by

$$
\overrightarrow{\mathbf{F}}(x)=(3 x-2) \hat{\mathbf{i}} \mathrm{N}
$$

Determine the work done in moving the box to a distance of $5 \mathrm{~m}$ if its initial position was $1 \mathrm{~m}$.

\section{Question 9: Quantitative solution linguistic representation}

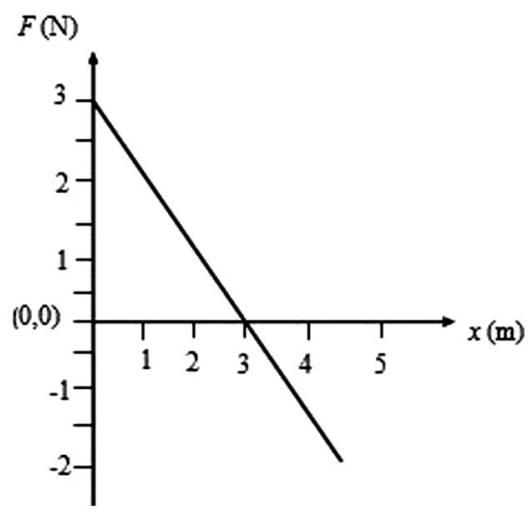

FIG. 27. Force-position graph requesting qualitative solution. 
A $10 \mathrm{~kg}$ box is moved along a rough horizontal surface over a distance of $15 \mathrm{~m}$ by a $20 \mathrm{~N}$ force applied at an angle of $30^{\circ}$ to the horizontal. The coefficient of kinetic friction between the box and the rough surface is 0.25 . Determine the total work done on the box.

Question 10: Quantitative solution from graphical representation

The relationship between the pressure and volume of a gas is shown in Fig. 28.

Determine the work done by the gas when the volume is increased from $5 \times 10^{-3} \mathrm{~m}^{3}$ to $15 \times 10^{-3} \mathrm{~m}^{3}$.

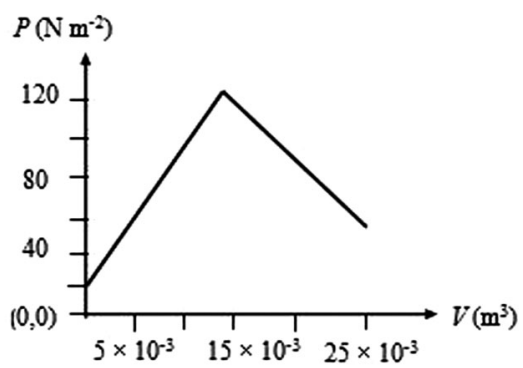

FIG. 28. Pressure-volume graph requesting quantitative solution.
[1] D. Hestenes, Modeling games in the Newtonian World, Am. J. Phys. 60, 732 (1992).

[2] I. Halloun, Schematic modeling for meaningful learning of physics, J. Res. Sci. Teach. 33, 1019 (1996).

[3] I. Halloun, Schematic concepts for schematic models of the real world: the Newtonian concept of force, Sci. Educ. 82, 239 (1998).

[4] J. D. Gobert and B.C. Buckley, Introduction to modelbased teaching and learning in science education, Int. J. Sci. Educ. 22, 891 (2000).

[5] W. S. Zimmerman and S. Cunningham, in Visualisation in Teaching and Learning Mathematics, edited by W. Zimmerman and S. Cunningham (Mathematical Association of America, Washington, DC, 1991).

[6] R.R. Cadmus, Jr., A video technique to facilitate the visualization of physical phenomena, Am. J. Phys. 58, 397 (1990).

[7] L. T. Escalada and D. A. Zollman, An investigation on the effects of using interactive digital video in a physics classroom on student learning and attitudes, J. Res. Sci. Teach. 34, 467 (1997).

[8] I. M. Greca and M. A. Moreira, Mental models, conceptual models, and modeling, Int. J. Sci. Educ. 22, 1 (2000).

[9] D. N. Rapp, in Visualization in Science Education, edited by J. K. Gilbert (Springer, Dordrecht, 2007).

[10] B. Tversky, in Visualization in Science Education (Ref. [9]).

[11] J.D. Gobert, in Visualization in Science Education (Ref. [9]).

[12] S. Ainsworth, DeFT: A conceptual framework for considering learning with multiple representations, Learn. Instr. 16, 183 (2006).

[13] P. B. Kohl and N. D. Finkelstein, Student representational competence and self-assessment when solving physics problems, Phys. Rev. ST Phys. Educ. Res. 1, 010104 (2005).

[14] S. Kalyuga, P. Chandler, and J. Sweller, Managing splitattention and redundancy in multimedia instruction, Appl. Cogn. Psychol. 13, 351 (1999).

[15] J. Clement, Model based learning as a key research area for science education, Int. J. Sci. Educ. 22, 1041 (2000).
[16] W. Schnotz and M. Bannert, Construction and interference in learning from multiple representation, Learn. Instr. 13, 141 (2003).

[17] D. Sokoloff, P. Laws, and R. Thornton, RealTime Physics, Vernier Software, 1994.

[18] P.W. Laws, Calculus-based physics without lectures, Phys. Today 44, No. 12, 24 (1991).

[19] D. W. Russell, K. B. Lucas and C. J. McRobbie, The role of microcomputer-based laboratory display in supporting the construction of new understandings in kinematics, Res. Sci. Educ. 33, 217 (2003).

[20] G. Simpson, C. Hoyles, and R. Noss, Exploring the mathematics of motion through construction and collaboration, J. Comput. Assist. Learn. 22, 114 (2006).

[21] C. A. Berg and P. Smith, Assessing students' abilities to construct and interpret line graphs: Disparities between multiple-choice and free-response instruments, Sci. Educ. 78, 527 (1994).

[22] R. J. Beichner, Testing student interpretation of kinematics graphs, Am. J. Phys. 62, 750 (1994).

[23] L. C. McDermott and P. S. Shaffer, Research as a guide for curriculum development: An example from introductory electricity. Part I: Investigation of student understanding, Am. J. Phys. 60, 994 (1992).

[24] I. Testa, G. Monroy, and E. Sassi, Students' reading images in kinematics: The case of real-time graphs, Int. J. Sci. Educ. 24, 235 (2002).

[25] P. Colin, F. Chauvet, and L. Viennot, Reading images in optics: Students' difficulties and teachers' views, Int. J. Sci. Educ. 24, 313 (2002).

[26] D.E. Meltzer, Relation between students' problemsolving performance and representational format, Am. J. Phys. 73, 463 (2005).

[27] P. B. Kohl, D. Rosengrant, and N. D. Finkelstein, Strongly and weakly directed approaches to teaching multiple representation use in physics, Phys. Rev. ST Phys. Educ. Res. 3, 010108 (2007).

[28] B. Ibrahim and N. Sanjay Rebello, Representational task formats and problem solving strategies in kinematics and work, Phys. Rev. ST Phys. Educ. Res. 8, 010126 (2012). 
[29] A. Van Heuvelen and D.P. Maloney, Playing physics jeopardy, Am. J. Phys. 67, 252 (1999).

[30] B.E. Hinrichs, Using the system schema representational tool to promote student understanding of Newton's third law, AIP Conf. Proc. 790, 117 (2005).

[31] R. J. Dufresne, W. J. Gerace, and W. J. Leonard, Solving physics problems with multiple representations, Phys. Teach. 35, 270 (1997).

[32] D. Rosengrant, A. Van Heuvelen and E. Etkina, Free-body diagrams: Necessary or sufficient?, AIP Conf. Proc. 790, 177 (2005).

[33] C. J. DeLeone and E. Gire, Is instructional emphasis on the use of non-mathematical representation worth the effort?, AIP Conf. Proc. 818, 45 (2006).

[34] D. Rosengrant, A. Van Heuvelen and E. Etkina, Case study: Students' use of multiple representations in problem solving, AIP Conf. Proc. 818, 49 (2006).

[35] T. Seufert, Supporting coherence formation in learning from multiple representations, Learn. Instr. 13, 227 (2003).

[36] J. Van der Meij and T. de Jong, Supporting students' learning with multiple representations in a dynamic simulation-based learning environment, Learn. Instr. 16, 199 (2006).

[37] G. Polya, How to Solve It (Princeton University Press, Princeton, NJ, 1957).

[38] J.D. Bransford and B.S. Stein, The IDEAL Problem Solver (W. H. Freeman, New York, 1984).
[39] D. H. Jonassen, Learning to Solve Problems: A Handbook for Designing Problem-Solving Learning Environments (Routledge, New York, 2011).

[40] R. K. Coll, B. France, and I. Taylor, The role of models/ and analogies in science education: Implications from research, Int. J. Sci. Educ. 27, 183 (2005).

[41] P. Johnson-Laird, Mental Models (Harvard University Press, Cambridge, MA, 1983).

[42] I. M. Greca and M.A. Moreira, The kinds of mental representations-models, propositions and images-used by college physics students regarding the concept of field, Int. J. Sci. Educ. 19, 711 (1997).

[43] M. T. H. Chi, P. J. Feltovich, and R. Glaser, Categorization and representation of physics problems by experts and novices, Cogn. Sci. 5, 121 (1981).

[44] R. Kozma, The material features of multiple representations and their cognitive and social affordances for science understanding, Learn. Instr. 13, 205 (2003).

[45] B. Ibrahim, A. Buffler, and F. Lubben, Profiles of freshman physics students' views on the nature of science, J. Res. Sci. Teach. 46, 248 (2009).

[46] B. Ibrahim, Ph.D. thesis, University of Cape Town, 2009.

[47] E. Etkina, A. Van Heuvelen, S. White-Brahmia, D. T. Brookes, M. Gentile, S. Murthy, D. Rosengrant, and A. Warren, Scientific abilities and their assessment, Phys. Rev. ST Phys. Educ. Res. 2, 020103 (2006). 